\title{
Revisitando uma "coleção de cabeças": notas sobre a musealização de restos mortais do cangaço
}

\author{
Clovis Carvalho Britto \\ Professor Doutor da Universidade Federal de Sergipe, Laranjeiras, Brasil \\ clovisbritto5@hotmail.com
}

\begin{abstract}
Resumo $\mathrm{O}$ trabalho investiga a musealização de despojos mortais do cangaço a partir da trajetória das cabeças de Maria Bonita e Lampião. Analisa a coleção de cabeças sob o ponto de vista do "consumo do trágico", sublinhando como contribuíram para a efetivação de um antimuseu e para os debates sobre questões éticas em torno da necrofilia nos museus. Visualiza como a musealização das cabeças dos cangaceiros contribui para a reconstrução das interfaces entre Antropologia, Museologia e museus, evidenciando as transformações nesses artefatos: os despojos humanos como provas de crime; troféus de guerra; objetos científicos; e coleções museológicas. As análises destacam estratégias de arquivamento, fabricação e consagração de legados nas tramas de uma economia de símbolos sobre o cangaço e os usos sobre os despojos humanos (tidos como objetos sensíveis) nos museus.
\end{abstract}

Palavras-chave: Restos mortais, cangaço, musealização, objetos sensíveis, ética.

A cabeça de Maria Bonita deu entrada às 10 horas na noite de 31 de julho de 1938 no Serviço Médico Legal do Estado de Alagoas em mau estado de conservação, razão por que não foi retirado o encéfalo, já reduzido a uma pasta esbranquiçada e amorfa que se escoava pelo orificio occipital. As partes moles infiltradas não permitiram fossem melhor apreciados os traços fisionômicos da companheira de Lampião, os quais, aliás, não pareciam desmentir o apelido que lhe deram.

Aparentava ser uma mulher de trinta a trinta e cinco anos de idade. À primeira impressão, o que mais prende atenção em vê-la é a sua testa alta e de todo vertical, cabelos negros, longos, finos e lisos, arrumados em trança pendente. Tez morena clara. Pode ser incluída no grupo dos brasileiros 
xantodermas da

classificação de Roquette Pinto. Perímetro cefálico é de 57 centímetros. O diâmetro anteroposterior máximo é de 195 milímetros. Índice cefálico, 33. Portanto, braquicéfala. O comprimento total do rosto alcança a 190 milímetros. O comprimento total da face é de 120 milímetros. O comprimento simples da face é de 72 milímetros. Diâmetro bizigomático ou transverso máximo da face, 153 milímetros. Índice facial de Broca, 47,0. Lábios grossos, sendo a largura da cavidade bucal de 45 milímetros. Dentes pequenos, bem plantados e em excelente estado de conservação. Olhos castanhos escuros. São estes os principais elementos colhidos, trançando-se o perfil antropológico de Maria Bonita. Lages Filho (1938 apud Santelmo, 1954, p. 70)

A epígrafe consiste em fragmento do relatório médico relativo aos restos mortais de Maria Bonita, examinados três dias depois de seu assassinato em Angico, sertão de Sergipe. O exame foi elaborado por José Lages Filho, chefe do Serviço Médico-Legal de Polícia do Estado de Alagoas, e concluiu que a companheira de Lampião não possuía "nenhum estigma de degenerescência". Após ser decapitada, juntamente com onze cangaceiros, teve a cabeça exibida na escadaria da Prefeitura de Piranhas, em Alagoas, e, posteriormente, apresentada em cortejo pelas cidades de Maceió e Salvador, sendo mumificada e exposta no Museu Nina Rodrigues até 1969, quando foi enterrada e substituída por uma máscara mortuária feita a partir dela.

$\mathrm{O}$ exame e a mumificação da cabeça remetem às discussões de Michel Foucault (1987) quando investigou a genealogia do método clínico e o lugar do homem como objeto de reflexão científica, o que teria gerado uma mudança epistemológica no olhar médico. Segundo destacou, os estudos de anatomia patológica empreendida na França no final do século XVIII ao "abrir alguns cadáveres" contribuíram para a percepção de um espaço discursivo para o desvelamento de verdades sobre a morte, fenômenos patológicos e o corpo humano em geral. Meu argumento é que no caso do cangaço a abordagem clínica dos despojos mortais contribuiu para o estabelecimento de uma "explosão discursiva". A partir desse conceito, Foucault (1988) examinou um conjunto de práticas/discursos na longa duração, compreendendo como são atravessados por restrições ao impactarem enunciados (de que forma seria possível dizer) e enunciações (quem diz e possibilidades de dizer).A "explosão discursiva" pode ser visualizada como um mecanismo de selecionar as palavras, os lugares e as formas de dizer: "controle dos enunciados e das enunciações, [e uma] [...] proliferação de discursos no campo do exercício do poder; uma produção voltada para a condução das condutas e a produção coletiva da subjetividade, visando a mudanças socioculturais." (Fernandes, 2011, p. 13).

É por isso que é possível conceber a decapitação e posterior musealização da cabeça de Maria Bonita como um fato dramático. ${ }^{1}$ Todavia, a permanente "explosão discursiva"

1 Vários personagens emblemáticos na história brasileira foram decapitados, como estratégia exemplar e didática ou em virtude dos estudos de antropologia física. O fecho dramático, aliado a uma série de estratégias, contribuiu para a mitificação em torno de suas trajetórias. Nesse sentido, além de Maria Bonita, Lampião e dos nove cangaceiros de seu bando, são ilustrativas as mortes de Tiradentes, Antônio Conselheiro, Ganga Zumba e Zumbi. 
em torno desse fato também produz um conjunto de imagens repletas de dramaticidade. $\mathrm{Na}$ verdade, consistiu em fato que inaugurou uma série de outras ações não menos dramáticas. A representação (reapresentação) de discursos como esses contribui para reencontrar no presente a dramaticidade, traduzi-la em outras formas de expressão e para diferentes públicos. Surge, no caso dos fatos trágicos, uma representação da memória trauma que encontra na imaginação uma forma para sua narração (Seligmann-Silva, 2008).

Exemplo característico dessa representação consiste na crônica de Aurélio Buarque de Holanda (1995) que, ao descrever a exposição das cabeças decapitadas, envolve o texto literário com tamanha tensão que constrói uma dramaturgia da memória:

Desenrola-se o drama. O trágico se confunde com o grotesco. Quase nos espanta que não haja palmas. Em todo caso, a satisfação da assistência traduzse por alguns risos mal abafados e comentários algo picantes, em face do grotesco. O trágico, porém não arranca lágrimas. Os lenços são levados ao nariz: nenhum aos olhos. A multidão agita-se, freme, sofre, goza, delira. E as cabeças vão saindo, fétidas, deformadas, das latas de querosene - as urnas funerárias -, onde o álcool e o sal as conservam, e conservam mal. Saem suspensas pelos cabelos, que, de enormes, nem sempre permitem, ao primeiro relance, distinguir bem os sexos. Lampião, Maria Bonita, Enedina, Luiz Pedro, Quinta-Feira, Cajarana, Diferente, Caixa-de-Fósforo, Elétrico Mergulhão... (Holanda, 1995, p. 2).

Esses episódios consistem em formas de expressão dramáticas, comunicando situações limítrofes. As cenas relatadas são espécies de atos de um mesmo drama, reapresentado para diferentes assistências a partir da fotografia, das matérias jornalísticas, dos relatórios médico-legais, dos cortejos e das exposições museológicas. Cada uma dessas formas de expressão reverbera e reelabora, ao seu modo, uma tensão marcada pela tragicidade e seus desdobramentos simbólicos.

Isso é significativo quando rememoro que a minha aproximação com esse tema ocorreu em virtude dessas estratégias de reverberação do drama do cangaço por meio de fotografias e objetos tridimensionais expostos em diferentes museus do Nordeste, especialmente o Museu do Instituto Histórico e Geográfico de Alagoas, em Maceió-AL; o Museu Histórico de Sergipe, em São Cristóvão-SE; e o Memorial da Universidade Tiradentes, em Aracaju-SE. Essa proximidade, associada ao meu interesse pelos acervos dos museus-casas, contribuiu para que entre 2014 e 2016 realizasse pesquisas sobre os processos de musealização no Museu-Casa de Maria Bonita, em Malhada da Caiçara, Paulo Afonso-BA (Britto, 2016a).

O museu-casa, inaugurado em 23 de setembro de 2006, está localizado em uma área de difícil acesso a $55 \mathrm{~km}$ de Paulo Afonso, sendo $17 \mathrm{~km}$ em estrada de chão que atravessa a caatinga. A maioria do público recorre ao auxílio de guias de turismo da região que cobram uma taxa de setenta reais pelo percurso, valor acrescido de mais cento e trinta reais para aqueles que não possuem transporte. Existem poucas residências ao longo do 
trajeto e no povoado de Malhada da Caiçara, que ocasionalmente recebe o sinal de uma operadora de telefonia móvel.

Os moradores sobrevivem com água das cacimbas coletadas durante os meses de chuva. Muitas vezes, nos períodos de longa estiagem, a prefeitura envia caminhões pipa para reabastecer as mesmas. Nos meses de junho e julho, em virtude das chuvas, a estrada costuma ficar interditada. O museu-casa não possui energia elétrica e permanece fechado. Familiares de Maria Bonita que residem ao lado do museu são responsáveis por abri-lo toda vez que surge algum interessado. O museu é particular, propriedade da família da cangaceira, e é mantido com os recursos provenientes da taxa para visitação.

Essa breve descrição do museu e da região em que está localizado é necessária em virtude de explicitar o meu primeiro contato com o universo do cangaço e com a musealização de restos mortais. Isso é importante na medida em que devido à dispersão dos objetos do cangaço e às precárias condições de segurança, a narrativa museológica é expressa majoritariamente a partir de fotografias de Maria Bonita registradas por Benjamin Abrahão, em 1936 (Araújo, G., 2011). Embora nenhuma das fotos remeta ao período em que ela residiu na casa, elas colaboram para criar a ilusão da presença da cangaceira, suprindo a inexistência dos objetos pertencentes a Maria Bonita naquele espaço.

Desse conjunto documental, a exposição privilegiou as fotografias das cabeças de Maria Bonita, fator que contribuiu para que minhas análises evidenciassem com maior vigor a trajetória dos restos mortais da cangaceira e, consequentemente, as ações de musealização em torno desses artefatos. A partir do contato com esses documentos expostos foi possível problematizar de que modo o trabalho com a memória sobre situações críticas também se reveste de tensões que atravessam as representações instituídas pelo fazer museológico.

Neste artigo reconheço as configurações de uma economia de símbolos (Bourdieu, 2007) nas narrativas relacionadas a "eventos críticos", tendo como estudo de caso a musealização de despojos mortais do cangaço e como recorte a trajetória das cabeças de Lampião e de Maria Bonita. A partir das fotografias expostas no Museu-Casa de Maria Bonita, de conversas com os responsáveis pela exposição museológica e de documentos relacionados à temática do cangaço, evidencio como essa "coleção de cabeças" contribuiu para a instituição de debates sobre questões éticas em torno dos restos mortais nos museus.

A categoria "evento crítico" se relaciona com a linguagem do sofrimento e a experiência traumática, a partir das tramas que envolvem dramas individuais e coletivos que resultam em rupturas nas ações cotidianas (Das, 1995). Portanto, o "consumo do trágico" seria a difusão e hipervalorização de crenças em torno da catástrofe, da dor e/ ou da morte e que embora possa ser evidenciado em inúmeros espaços simbólicos, meu interesse é analisá-lo nas exposições museológicas relacionadas ao cangaço, com destaque para os usos da cabeça decapitada na construção de narrativas sobre Maria Bonita e Lampião.

Desse modo, reconheço a musealização como uma prática seletiva que ao realizar os processos museológicos sobre os objetos revela os embates em torno dos processos de exclusão e de silenciamento de memórias. Pensamento que dialoga com Marília Xavier 
Cury (2005) quando sublinhou essa ação como um processo que abarca um conjunto de ações sobre objetos (aquisição, conservação, documentação, pesquisa, comunicação), iniciado "ao selecionar um objeto de seu contexto e completa-se ao apresentá-lo publicamente por meio de exposições, de atividades educativas e de outras formas" (p. 26).

O "consumo do trágico" contribuiria para a fabricação de determinados discursos, tornando-se valor estratégico no modo como instituições e indivíduos manipulam os usos políticos sobre o passado produzindo legados. Isso ganha força em casos quando a musealização evoca um conjunto de memórias em torno de acontecimentos trágicos, a exemplo do cangaço que entrecruza discussões sobre o sertão e, especialmente, a seca, a violência e a resistência metamorfoseados nas figuras de seus personagens centrais.

\section{“Caveiras errantes": itinerários da musealização}

A escolha dos itinerários da musealização das cabeças dos cangaceiros - com recorte especial para a trajetória de Lampião e Maria Bonita - se deveu à força que esses dois personagens possuem na economia de símbolos que reinventa o cangaço e o Nordeste (Albuquerque Júnior, 2011); pela minha experiência anterior com acervos relacionados ao cangaço (Britto, 2016b); e, especialmente, pelos debates em torno da musealização de restos mortais no campo da Antropologia e da Museologia (Kim, 2012; Serra, 2006).

Conforme destaquei anteriormente, em 31 de julho de 1938, três dias depois de suas mortes em Angico, em Sergipe, as cabeças dos cangaceiros foram encaminhadas para José Lages Filho, chefe do Serviço Médico-Legal de Polícia do Estado de Alagoas. Em seu relatório, concluiu que a companheira de Lampião não possuía "nenhum estigma de degenerescência" (Santelmo, 1954, p. 70). Após ser decapitada teve a cabeça exposta e fotografada na escadaria da Prefeitura de Piranhas, em Alagoas, e, posteriormente, exposta no Museu Nina Rodrigues, em Salvador, até 1969 quando foi enterrada, sendo substituída por uma máscara mortuária.Em 2002, depois de exumadas, as cabeças de Lampião e Maria Bonita foram devolvidas aos seus herdeiros que ainda intentam construir um memorial para abrigá-las.

A proposta dialoga com as orientações de Celso Castro e Olívia Cunha (2005) ao investigarem as interfaces entre pesquisa de campo e acervos, possibilitando a concepção do arquivo como "como campo povoado por sujeitos, práticas e relações suscetíveis à análise e à experimentação antropológica." (p. 4). Dessa forma, pretendo sublinhar algumas dessas possibilidades analíticas tendo como exemplo os acervos sobre restos mortais do cangaço arquivados em diferentes museus, especialmente as fotos sobre a trajetória desses despojos expostas no Museu-Casa de Maria Bonita.

A fabricação/consagração de legados envolve uma rede de memórias que ora se apoiam ou se cruzam, ora se excluem em um processo de montagem do personagem protagonista/anfitrião do espaço como emblemático na poética e na política que "imortaliza" determinados agentes. Tais embates contribuem para a instituição de uma 
“explosão épica" em torno de determinados enredos, ou seja, o processo de invenção da imortalidade, a exemplo de quando uma pessoa passa a integrar o patrimônio de uma nação ou região, tornando-se homem ou mulher-monumento (Abreu, 1994). Esse processo é materializado em diversas formas de expressão (como no folheto de cordel, no cinema, na música, nas artes plásticas). Além disso, adquire ressonância na musealização de temáticas ou de personagens cujas trajetórias são fruto dessa fabricação prévia (narrativa de uma narrativa), a exemplo da saga do cangaço e da dimensão épica de seus expoentes. Tornam-se repertórios que podem ser manipulados para legitimar diferentes versões e interesses, conforme destacou Durval Muniz de Albuquerque Júnior (2011, p. 230-232):

O Estado Novo pôs a funcionar toda uma maquinaria de esquecimento do cangaço. A grande imprensa é intimada a silenciar sobre seus feitos; a gritar, em grandes manchetes, o seu fim. Os cangaceiros, a partir desse momento, são tratados como criminosos comuns. Estes não passam de hostes de bandidos que ainda perambulam pelo sertão. [...] O silêncio se faz ouvir e o cangaceiro mergulha nas sombras para brilhar como 'símbolo de um passado', vencido pela ordem e pela civilização. Estes homens permanecem vivos, no entanto, na memória popular, nas produções culturais populares. $\mathrm{O}$ cangaceiro se torna um mito, no momento em que deixa de fazer história. Quando ainda estava em atividade, na década de trinta, sofria a condenação quase unânime dos intelectuais. Mesmo entre os tradicionalistas, o cangaceiro saudoso era o cangaceiro morto; era aquele que tinha vivido num passado idílico. [...] As narrativas e obras sobre o cangaço enfatizam o seu lado cruel, violento, selvagem, desenhando o Nordeste como o espaço da valentia e da morte estúpida e gratuita, por puro sadismo, por prazer, ou por espírito de vingança. [...] A leitura que a esquerda faz do cangaço se altera, na década de quarenta, exatamente no momento em que é anunciado seu fim. Passa a ser lido como um signo de rebelião, como um indício da possível revolta futura. A mitificação do cangaço se dá também por uma verdadeira postura voluntarista, pouco crítica e analítica das condições históricas e sociais do surgimento do cangaceiro. Este já não é vítima de uma sina, mas de uma sociedade. É, principal e simploriamente, vítima do latifúndio

Essa dimensão épica do cangaço é resumida por Simão Santos (2015) quando analisou sua representação na literatura de cordel. Em suas interpretações, a figura do cangaceiro representa um ideal heroico, entremeado por medo e admiração, tornandose "a representação de um mito local, com vistas, inclusive, para a afirmação coletiva do povo nordestino e brasileiro" (Santos, 2015, p. 17). Informa que, na mítica popular, o cangaceiro tido como herói não matava de forma banal, nem roubava sem motivos: "se o faziam, era pela sobrevivência e necessidade. Se não trabalhavam, era porque, perseguidos pelo governo e por inimigos, não tinham chão para se fixar. Nunca se entregavam. Preferiam a honra da morte em combate" (Santos, 2015, p. 71). Além disso, destaca que a distância no tempo contribuiu para depurar Lampião para o imaginário popular e de criação poética, característica típica do canto épico. Os cangaceiros passaram a ser vistos como representantes de uma cultura telúrica, espécie de símbolo de um nacionalismo 
heroico: "do enfrentamento do sistema político, à obstinação em ombrear valentemente com a classe dominante que os perseguia, até a busca pela natureza nordestina que, paradoxalmente, os abrigava e lhes era temerosa" (Santos, 2015, p. 89).

O pesquisador também descreve alguns fatos que contribuíram para a construção dos cangaceiros como heróis: dar a vida pelos companheiros e pela causa como sinal de honradez; enfrentar, com destemor e número desigual de combatentes e armas, os poderosos locais; duelar e vencer as forças do governo; sobreviver a um ambiente hostil, marcado pela seca, pela fome e por emboscadas; representar a valentia ao percorrer longas distâncias e de forma nômade; possuir dons sobrenaturais que os protegiam das adversidades etc. Enredo que pode ser estendido às heroínas do cangaço, sintetizadas na figura de Maria Bonita, e complementado pelo fato de que essas mulheres modificaram o curso de suas vidas em nome de um amor tamanho ao ponto de por ele entregar seus filhos e dar a própria vida.

Esses discursos a respeito do cangaço são traduzidos em diversas expressões artísticas - na fotografia, no cinema, na música, na literatura, na xilogravura, no teatro, no artesanato, na moda (Ferreira; Araújo, 2011) - e em exposições museológicas brasileiras. ${ }^{2}$ Resultam em representações que também colaboram para a invenção e/ou consolidação de determinadas crenças a respeito de seus personagens.

Especificamente no caso dos museus e coleções, é necessário citar os argumentos de Frederico Pernambucano de Mello (2010) quando considera que os objetos do cangaço integrantes de coleções públicas e particulares: 1 - consistem em peças raras em virtude da repressão sofrida por seus usuários, no intuito de "abater os sinais de rebeldia que imantavam esses troféus a olhos oficiais e relegando praticamente ao vazio as vitrines dos museus sobre os movimentos sociais insurgentes de nossa história"; 2 - emanam de circunstâncias de "conflito sempre possível, com a perspectiva da morte violenta do usuário insinuando-se no cotidiano, o que as faz refertas de uma simbologia mística, exacerbada em profusão dos signos de defesa e rebate" (Mello, 2010, p. 20). Vistos de acordo com minha chave interpretativa, esses objetos se transformaram em testemunhos materiais (e, ao mesmo tempo, simbólicos) que reforçam a dimensão épica (e mítica) do cangaço.

No caso do cangaço essa dimensão assume contornos épico-dramáticos e os restos mortais de seus protagonistas consistem em um dos principais acervos cuja trajetória acompanhou as perspectivas deterministas e as transformações da antropologia criminal e dos próprios museus (Serra, 2006).

2 São exemplos de instituições museológicas que possuem acervos relacionados ao cangaço: $\mathrm{Mu}$ seu Histórico Nacional, no Rio de Janeiro/RJ; Museu do Cangaço/Fundação Cultural Cabras de Lampião em Serra Talhada/PE; Museu do Cangaço e da Cidade de Triunfo, em Triunfo/PE; Museu-Casa de Maria Bonita, em Paulo Afonso/BA; Museu do Cangaço, no Povoado de Alagadiço em Frei Paulo/SE; Memorial da Universidade Tiradentes, em Aracaju/SE; Museu Histórico de Sergipe, em São Cristóvão/SE; Museu do Instituto Histórico e Geográfico de Alagoas, em Maceió/ AL; e Museu do Sertão, em Piranhas/AL. 
Conforme destaquei, após o assassinato em Angico, as cabeças dos cangaceiros foram expostas na escadaria da Prefeitura de Piranhas, em Alagoas. (Figura 1). A foto datada de 28 de julho de 1938, de autoria não identificada, consiste em uma das imagens mais divulgadas do acervo sobre o cangaço. Nela, as onze cabeças - incluindo a de Maria Bonita - estão dispostas nas escadarias, ladeadas por objetos pessoais apreendidos. Destacam-se, no cenário montado para a fotografia, a presença de armamentos, chapéus, embornais e de duas máquinas de costura da marca Singer.

De acordo com Marcos Clemente (2007), as cabeças são apresentadas em simetria, "algumas apoiadas por calços de pedra, cabelos desgrenhados, feições rígidas, olhos fechados. A ordem de apresentação do escalão é inversa e quebra a hierarquia que tiveram em vida. No plano mais baixo, isolada, a cabeça de Lampião; acima a de Maria Bonita" (p. 4). O pesquisador também analisa que a cena parece ter sido forjada para desconstruir determinadas visões sobre o cangaço, apresentando um Lampião solitário, rompendo com a imagem lendária do casal Lampião e Maria Bonita, visto que esta não aparece ao seu lado. Do mesmo modo, os pertences do grupo foram colocados aleatoriamente, sem a identificação de seus donos, reunidos como espólio material do cangaço: duas máquinas de costura Singer, pistolas, mosquetões, punhais longos e medianos, chapéus de couro com abas viradas e pontuados com estrelas, embornais, cartucheiras, peças de indumentária adornadas com moedas de ouro e traços geométricos.

Figura 1 - Cabeças expostas na escadaria da Prefeitura de Piranhas-AL, 1938

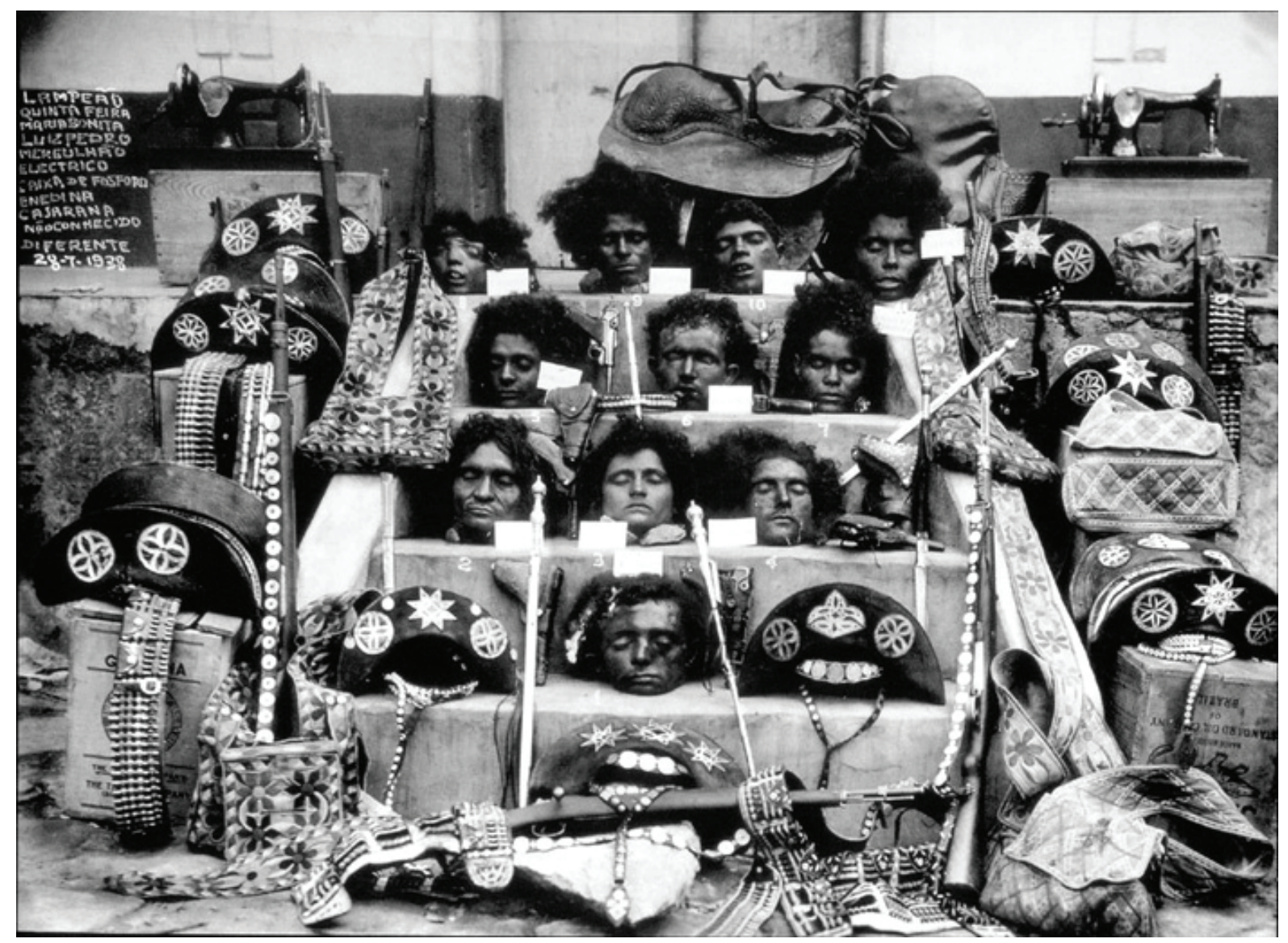

Fonte: Autoria não identificada. 
Em seguida as cabeças foram examinadas por Lages Filho, cujos estudos estavam orientados pela teoria da degenerescência,sendo um dos expoentes das teorias lombrosianas no Brasil; e, posteriormente, foram examinadas por Estácio de Lima, que as estudou no Instituto Médico-Legal de Salvador (Lima, 1965). Portanto, não é de se estranhar que após a decapitação vários museus de antropologia criminal do Brasil e da Europa solicitaram os restos mortais ou sua reprodução em moldes de gesso (a exemplo do Instituto MédicoLegal de Maceió, do Instituto Guilherme II, de Berlim, e do Instituto Nina Rodrigues de Salvador [renomeado de Museu Estácio de Lima e destino escolhido para a exposição]), e, nessa fase, os crânios já não possuíam apenas o estatuto de objeto científico, mas o de objeto museológico (Grunspan-Jasmin, 2001).

Segundo analisou Élise Grunspan-Jasmin (2001), uma das pautas consistia na conservação das cabeças por meio de um cientista ligado às belas-artes. Em 1959, as cabeças eram as "peças mestras" do museu "aquelas objetos não eram estudados havia anos; tinham inclusive perdido o caráter humano e era dificil identificá-los." (Grunspan-Jasmin, 2001, p. 336). Especificamente sobre a cabeça de Maria Bonita, informa que ela estava deformada, sendo impossível identificar qualquer traço de beleza. Todavia, despertava a curiosidade do público que, provavelmente, não visitaria a exposição museológica caso esses objetos não estivessem ali. Nessa década, iniciaram as discussões questionando o estatuto científico e museológico dos objetos e reivindicando sua sepultura. Alguns jornalistas e pesquisadores alegavam o artigo 212 do Código Penal referente à profanação de cadáveres.

Após 1969, as cabeças dos cangaceiros foram devolvidas às famílias e enterradas, sendo substituídas por fotografias que as mostravam tais como se apresentavam antes no museu, com a seguinte explicação: 'Estas cabeças foram expostas neste instituto para servir a ciência e a antropologia do cangaço’ (Grunspan-Jasmin, 2001, p. 339).

Conforme destacou Élise Grunspan-Jasmin (2001), o recurso às fotografias das cabeças ou cópias em gesso tornou-se uma prática comum nas exposições museológicas sobre o cangaço. Sublinha como exemplo a exposição do Museu do Instituto Histórico e Geográfico de Alagoas, demonstrando a amplitude da reapropriação dos cangaceiros para fins museológicos.

Situação que também dialoga com o Museu-Casa de Maria Bonita, situado no povoado de Malhada da Caiçara, em Paulo Afonso-BA, cuja exposição inaugurada em 23 de setembro de 2006 fornece elementos significativos para a monumentalização desse evento crítico. Nela, a narrativa sobre Maria Bonita é apresentada estritamente através da 
linguagem não-verbal, especialmente na "explosão discursiva" gerada pelas fotos sobre sua morte trágica. ${ }^{3}$

O Museu-Casa de Maria Bonita dedica uma sala em memória da morte da cangaceira. Neste espaço são expostas quatro fotografias mortuárias que destacam a cabeça de Maria, além de um fuzil (também existe outra arma similar exposta na sala do museu-casa) e uma máquina de costura. Certamente o intuito foi dialogar com os objetos que ladeavam os restos mortais nas escadarias da Prefeitura de Piranhas, em Alagoas, cuja foto também está exposta. As imagens foram selecionadas do arquivo do colecionador João de Sousa Lima, reproduzidas e emolduradas, apresentando diferentes trajetos sobre esse evento crítico que, por meio das fotos, ali foi musealizado.

As narrativas sobre as cabeças dos cangaceiros acionam uma economia de símbolos, gerando diversas narrativas em periódicos, livros e pesquisas acadêmicas. Também mobilizam o enredo de obras como Vida, aventuras e morte de Lampião e Maria Bonita, de Amador Santelmo (1954); O estranho mundo dos cangaceiros, de Estácio de Lima (1965); Lampião senhor do sertão: vidas e mortes de um cangaceiro, de Élise Grunspan-Jasmin (2001); Lampião e as cabeças cortadas, de Antônio Amaury Correa de Araújo e Luiz Rubem Bonfim (2008); e Maria Bonita: a mulher de Lampião, de Antônio Amaury Correa de Araújo (2009). Além disso, as cabeças dos cangaceiros se tornaram um dos principais atrativos do Museu de Antropologia Criminal da Bahia: "Elas eram expostas no museu como peças mestras, despertando a curiosidade do público, que talvez não o visitaria se elas não estivessem ali.' (Grunspan-Jasmin, 2001, p. 338).

Nesse sentido, convém destacar que após a devolução das cabeças para as famílias dos cangaceiros, as mesmas foram substituídas na exposição do Museu Estácio de Lima, em Salvador: "as infelizes cabeças foram substituídas por máscaras mortuárias feitas a partir delas, máscaras essas ainda em exibição no mesmo lugar” (Serra, 2006, p. 310). Também existe uma moldagem da cabeça de Lampião no Museu do Instituto Histórico e Geográfico de Alagoas, em Maceió, elaborada em gesso pelo escultor Lourenço Peixoto, em 1938, integrando a exposição museológica do instituto desde então (Silva, 2012).

3 No dia 28 de julho de 1938, o grupo de cangaceiros foi morto em combate na Grota do Angico, hoje pertencente a Poço Redondo/SE, por uma força volante comandada pelo tenente alagoano João Bezerra da Silva. Os onze cangaceiros que tiveram suas cabeças decepadas - alguns ainda em vida - foram:Virgulino Ferreira da Silva (Lampião); Maria Gomes de Oliveira (Maria Bonita); Enedina; Luis Pedro; Moeda; Quinta-Feira; Alecrim; Elétrico; Colchete; Mergulhão; e Macela. 
Figura 2 - Fotografias das cabeças de Maria Bonita, Lampião e cangaceiros

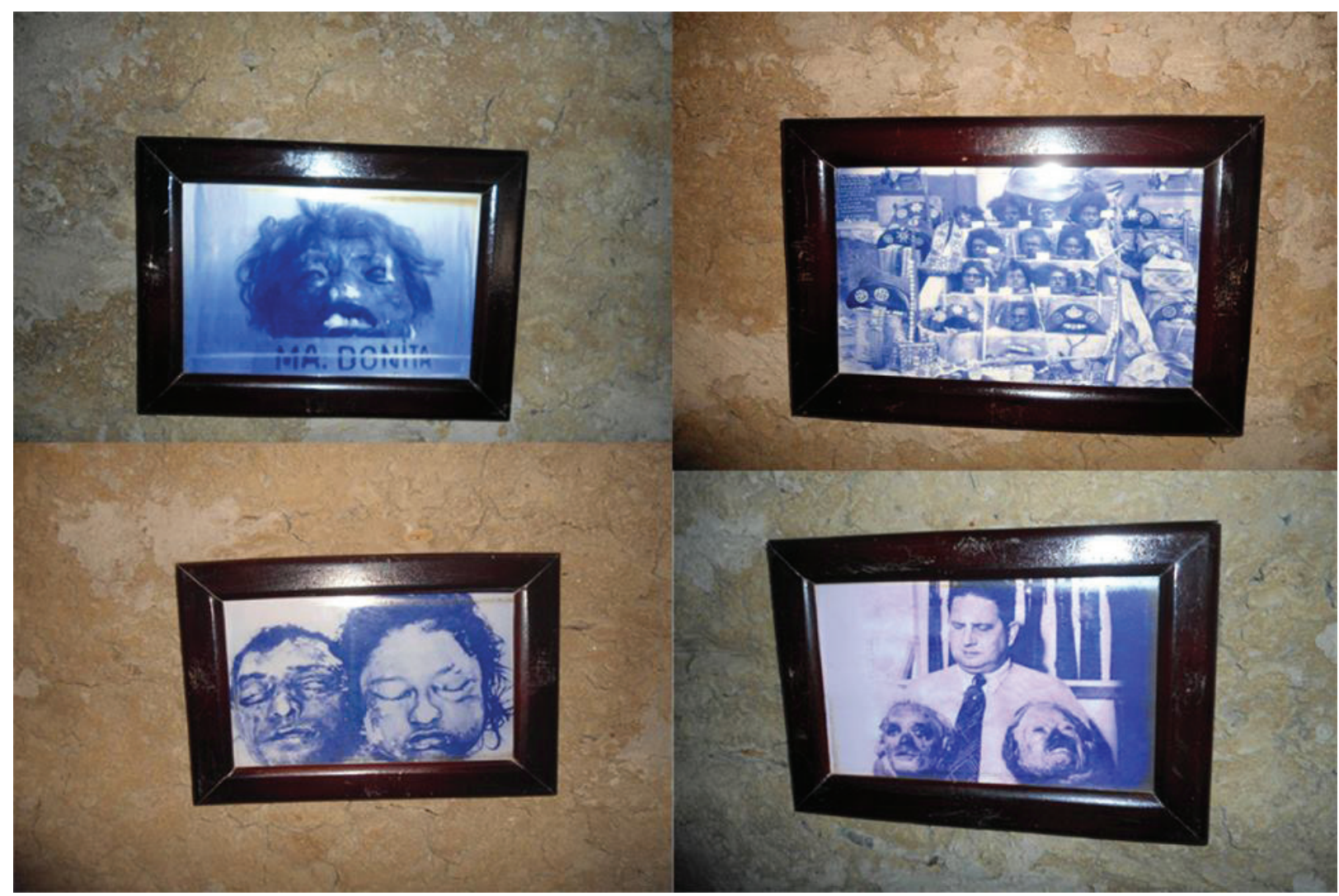

Fonte: Fotos do autor, 2015.

No Museu-Casa de Maria Bonita existem várias reproduções de fotografias das cabeças de Maria Bonita e de Lampião, algumas da exposição no então Museu Nina Rodrigues (Museu Estácio de Lima) (operação metalinguística que sublinha a musealização de uma musealização); e do médico-legista Charles Pittex analisando os dois crânios (Figura 2). Seria o registro dos "troféus macabros", nomenclatura dada por diversos jornalistas na época da morte dos cangaceiros, que se tornou para muitos uma forma de voyeurismo científico e atrativo turístico e museológico (Grunspan-Jasmin, 2001; Lima, 1965).

As fotos aparecem sem identificação, em espaço contíguo à “cozinha” do museu-casa. As quatro fotografias emolduradas foram afixadas sobre as paredes de taipa e colocadas juntamente com um fuzil e uma máquina de costura. A seleção e a apresentação desses indícios contribuíram para que a casa-natal de Maria Bonita também se transformasse em lugar de memória da morte, atrelando à exposição museológica fatos que ocorreram para além da casa. Esses objetos foram cuidadosamente selecionados para integrarem a exposição justamente por propiciarem uma ambientação trágica, sendo, inclusive, nomeados como integrantes da "sala macabra".

Desse modo, para além da relevância da trajetória e da dramaticidade de seu desfecho, percebo um intenso trabalho de produção e de gestão da memória sobre a cangaceira. Mais do que atribuir o protagonismo do seu futuro é perceber que, com a morte, Maria Bonita perdeu a titularidade sobre o seu próprio significado como agente. A ênfase 
analítica recai nas apropriações posteriores de sua memória, não desprezando, porém, as estratégias da titular no sentido de fabricar uma memória que sobrevivesse a morte. O que visualizo foram estratégias visando disciplinar as imagens da cangaceira que, até então, era conhecida como Maria de Déa (alcunha familiar) ou Maria do Capitão (nomenclatura no cangaço). Após sua morte iniciou o processo de fabricação da personagem, incluindo uma nova nomenclatura que inaugura esse rito de passagem:

É difícil saber com precisão quando o apelido de Bonita foi conjugado de modo decisivo ao nome de Maria para que, até hoje, ela seja conhecida dessa maneira. [...] Podem-se citar duas das ideias que são debatidas.A primeira é que o tal apelido foi dado a Maria por um policial volante que a achava bonita.A segunda, desenvolvida pelo pesquisador Jeová Franklin, é que a palavra bonita é fruto da tradução da palavra francesa Joli, que teria sido colocada junto ao nome Maria, em 1962, quando a imagem dela foi xilogravada pela primeira vez, ao lado de Lampião, para ilustrar um folheto de cordel sobre a história do casal de cangaceiros. Nas primeiras vezes em que Maria foi citada por jornais, o codinome adjetivado Bonita não acompanhava seu nome. Sabe-se que já em 1938 a revista Noite Ilustrada utilizava esses dois nomes, e que, portanto, pode-se refletir que Joli foi usado com benevolência à palavra incorporada Bonita. De certo modo, o apelido de Bonita cria uma doce expectativa sobre a cangaceira Maria e quebra a ideia de mulher dura e autoritária que foi criada sobre ela. Entretanto, não é parte da história biográfica de Maria, mas, sim, resultado da criação romântica da personagem Rainha do Cangaço pelas artes e pela mídia. O codinome Bonita foi incorporado de maneira tão forte que até as pessoas que conviveram com Maria de Déa passaram, depois a chamá-la de Maria Bonita (Ferreira; Araújo, 2011, p. 37-38).

A mitificação é evidente nos discursos difundidos pelo Museu-Casa de Maria Bonita, cujo tom épico perpassa toda a exposição. Isso é sintomático no título da biografia escrita por João de Sousa Lima (2005), idealizador do museu e doador da maioria dos objetos que integram a exposição museológica: A trajetória guerreira de Maria Bonita: a rainha do cangaço. Talvez, por essa razão, tenha dedicado uma sala do museu-casa para a memória de sua morte, episódio fundamental na fabricação de sua monumentalização. Nesse sentido, a inserção da foto de sua cabeça ladeada pelas máquinas de costura Singer, e a musealização de uma máquina de costura no mesmo espaço contribui para reforçar a faceta heroica da personagem que teria enfrentado diferentes adversidades e morrido na luta por suas convicções. Assim como nas demais exposições museológicas sobre o cangaço, a cabeça de Maria Bonita se tornou uma das principais peças da coleção, cujos restos mortais, atualmente sob a guarda da família, são representados em fotografias ou máscaras mortuárias em diferentes museus brasileiros. 


\section{Discursos errantes: os debates em torno de uma "coleção de cabeças"}

Ao longo deste texto apresentei alguns dos itinerários da musealização de despojos humanos tendo como roteiro de leitura os objetos necrófilos nos museus (Queiroz, 2014) a partir da musealização da cabeça de Maria Bonita. No caso de Lampião e Maria Bonita suas cabeças foram estudadas, musealizadas, enterradas e exumadas, trajetos relatados por Antônio Amaury Correa de Araújo (2011, p. 245-257), sob o título "Caveiras errantes":

Depois da decapitação dos 11 mortos, as cabeças foram levadas para Piranhas e foram fotografadas nos degraus da antiga escada existente, naqueles tempos, no prédio da prefeitura (modificada para uma disposição diferente nos dias atuais).Depois as cabeças foram colocadas em latas, das utilizadas originalmente para querosene, nas quais colocaram formol em quantidade que mal deu para as cabeças do 'Rei' e da 'Rainha'. As outras foram colocadas em álcool ou água com sal, no primeiro momento, e depois, já na capital alagoana, foram deixadas aos cuidados do dr. José Lages Filho, diretor do Serviço Médico-Legal de Maceió. Nessa oportunidade, dr. Lages examinou com maior interesse a cabeça de Lampião, visto ser a do chefe e estar em melhor estado de conservação. A de Maria Bonita fez companhia à de seu amásio ao serem levadas a Salvador, pelo dr. Arnaldo Silveira, onde permaneceram por 25 anos expostas à visitação pública no Museu do Instituto Médico-Legal Nina Rodrigues, de 1944 até 6 de fevereiro de 1969, quando foram então sepultadas no Cemitério da Quinta dos Lázaros. [As cabeças foram exumadas em 1. ${ }^{\circ}$ de fevereiro de 2002 a pedido da família de Lampião e Maria Bonita, conforme matéria da Revista Época, edição 214, de 24 de junho de 2002 transcrita a seguir]. [...] 'As cabeças de ambos, única parte que sobrou dos cadáveres, continua sem sepultura. Há algumas semanas, os crânios foram transferidos de Salvador para Aracaju, onde estão sob os cuidados de uma neta de Lampião e de Maria Bonita,Vera Ferreira. [...] Ela pretende montar em Aracaju o Museu do Cangaço. 'Lá, entre outras coisas, vou construir um memorial, onde meus avós enfim terão uma sepultura decente', diz ela. Enquanto isso não acontece os crânios permanecem em lugar não revelado. ${ }^{4}$ Vera teme que sejam roubados'.

$\mathrm{Na}$ verdade, as cabeças de Maria Bonita e Lampião se transformaram em metáfora e metonímia na economia de símbolos do cangaço. Foram metamorfoseadas em provas de crimes, objetos científicos e objetos museológicos, e hoje ocupam papel privilegiado no imaginário relacionado ao Nordeste brasileiro.Tal embate é tão significativo que as cabeças ainda não foram sepultadas, permanecendo com a família e tornando-se importante capital simbólico no intuito de legitimar a construção de um memorial.

Nesse sentido, as cabeças integraram uma coleção. Inicialmente visando legitimar um discurso de degenerescência, inspirado nas teorias lombrosianas e formando o que Ordep Serra (2006) reconheceu como um “anti-museu” ou um “mau exemplo”, mostra heteróclita 
que apresentava os cangaceiros como testemunhos de desvios, taras e patologias. Segundo o antropólogo, alguns defensores da mostra alegavam que os objetos deveriam permanecer expostos enquanto memória de um pensamento de época, de uma visão equivocada, mas histórica. No Museu Estácio de Lima, as cabeças dos cangaceiros eram apresentadas juntamente com anomalias genéticas, armas, drogas e objetos relacionados às religiões afrobrasileiras apreendidos pela polícia: "manter uma infâmia para preservar a lembrança dela não me parece coisa muito inteligente. Nem muito ética.” (Serra, 2006, p. 7).

Essa afirmação sobre a questão ética em torno da manutenção de museus com discursos contra os direitos humanos (ou antimuseus) consiste em uma temática fundamental no campo da Antropologia e da Museologia na contemporaneidade. Aqui me interessa promover um recorte que evidencia algumas notas preliminares sobre a ética em torno da musealização de despojos humanos, inspirada na exposição que durante décadas apresentou as cabeças mumificadas dos cangaceiros.

A partir de uma pressão promovida por familiares dos cangaceiros, jornalistas e pesquisadores, na década de 1960 os restos mortais foram devolvidos aos seus herdeiros, sendo, inclusive, objetos do Projeto de Lei n. 2.867 apresentado na Câmara dos Deputados em 24 de maio de 1965. Conforme destacou Élise Grunspan-Jasmin (2001), consistia também em uma forma da ditadura convencer que não se utilizaria dos antigos modos de repressão:

A proibição de expor um corpo mutilado era para ela a prova de que o Brasil tinha chegado a um estágio avançado de evolução social. Entretanto sabe-se hoje que a mutilação e a decapitação foram praticadas pelos militares sobre opositores políticos. [...] O inimigo tinha mudado de natureza, o problema era de ordem política mais do que regional e o perigo já não era o banditismo dos cangaceiros, e sim uma oposição política ao regime (Grunspan-Jasmin, 2001, p. 346).

Apesar do Projeto de Lei ter sido arquivado, ele resume um conjunto de iniciativas que visavam o enterramento das cabeças e, consequentemente, revelavam o mal-estar provocado pela musealização de despojos humanos. Além de exigir o sepultamento das cabeças de Maria Bonita e Lampião, o artigo $3 .^{\circ}$ do projeto ampliava a discussão ao afirmar que "fica proibido, em todo o território nacional, a exibição de órgãos do corpo humano de pessoas mortas, com objetivo lucrativo ou mesmo científico, cabendo punição de 5 a 10 anos de reclusão ao responsável".

O fato é que essa proposta exemplifica um conjunto de esforços da parte dos familiares e apoiadores visando evitar a exposição de órgãos humanos em instituições museológicas e garantir um enterro digno de seus entes. Essa movimentação contribuiu para que os restos mortais dos cangaceiros fossem sepultados em Salvador-BA, sendo as cabeças de Maria Bonita e Lampião enterradas em 6 de fevereiro de 1969.

Embora esse ato não tenha se estendido aos demais restos mortais musealizados, consiste em um marco desses debates no campo da Museologia e dos museus brasileiros. $\mathrm{Na}$ verdade, essa orientação somente ganhou respaldo entre nós a partir da assinatura do 
Código de Ética Profissional do Conselho Internacional de Museus (1986), especialmente no item relacionado aos restos humanos:

Os museus que mantém e/ou estão desenvolvendo coleções de restos humanos e objetos sagrados deveriam conservá-los em segurança e mantêlos cuidadosamente como sendo arquivos em instituições acadêmicas. Elas deveriam estar sempre disponíveis para pesquisadores e educadores qualificados, porém não para a curiosidade mórbida. Pesquisa sobre tais objetos, seu acondicionamento e cuidados precisam ser realizados de modo aceitável não somente para os colegas de profissão como para os de diferentes crenças, bem como para membros de uma comunidade em particular, como grupos étnicos ou religiosos. Apesar de, ocasionalmente ser necessário o uso em exposições interpretativas de restos humanos e outro material sensitivo, isso precisa ser feito com tato e com respeito pelos sentimentos de dignidade humana comum a todos os povos (p. 8).

Orientações reforçadas no campo dos museus com aprovação do Código Deontológico para Museus (2001), do Conselho Internacional de Museus, que dispõe sobre a obrigatoriedade dos despojos humanos serem colocados em segurança e tratados com respeito, concluindo que a utilização de "objetos sensíveis" em exposições deve respeitar os sentimentos de dignidade humana. O Código também destaca que o museu deve responder com diligência, respeito e sensibilidade aos pedidos de remoção de despojos humanos ou objetos com significado sagrado das exposições e responder, do mesmo modo, aos pedidos de devolução desses objetos.

A expressão "objetos sensíveis", embora extremamente subjetiva e genérica, vem sendo utilizada para se referir a coleções oriundas de contextos traumáticos, marcados pela violência física, psicológica ou pelo esbulho dos artefatos. Do mesmo modo, no caso de despojos humanos musealizados, pode ser aplicada no sentido subjetivo de objetos que ferem a sensibilidade, a honra e a dignidade humana, mas também no sentido objetivo, relacionado às sensações que provocam, a exemplo, as texturas e o odor exalado por essas pessoas-objetos ou seres-híbridos, para dialogarmos com o entendimento de Bruno Latour (1994).

A discussão se complexifica quando se envereda sobre os usos do corpo humano, as tensões em torno da bioética e normas correlatas, conforme dispôs Dominique Memmi (2003). Segundo suas análises, os dispositivos éticos contribuem, de algum modo, para a dessacralização dos corpos em benefício dos novos usos sociais e, ao mesmo tempo, atestam que a corporeidade consiste em um dos aspectos centrais da recomposição das relações entre Estado e "indivíduo".

$\mathrm{Na}$ verdade, se ao longo desta pesquisa as questões éticas em torno da exposição das cabeças ganharam evidência, essa temática comparece em grande parte das exposições fundadas na exploração colonial, em coleções arqueológicas e etnográficas. Se tais debates merecem ser estimulados e aprofundados, aqui problematizo em que medida a musealização de máscaras mortuárias e fotografias sobre despojos humanos também não consistem em exemplares de "objetos sensíveis" nos museus. 
Especificamente no caso das cabeças de Maria Bonita e Lampião, elas continuam sendo musealizadas em fotografias e máscaras mortuárias e acredito ser importante também discutir as questões éticas dos usos desses recursos. É possível pensar que tais imagens tornaram-se representativas na narrativa nacional e, portanto, foram naturalizadas. Todavia, a própria utilização das fotografias como fontes para este texto também foi objeto de meu questionamento, questionei em que medida seria ético apresentá-las como um exemplo dos debates em torno do "consumo do trágico". Optei por mantê-las em virtude das constantes vigilâncias comemorativas efetuadas pelos próprios descendentes de Maria Bonita e Lampião no intuito de difundi-las como um dos elementos demarcadores do épico no cangaço. (Ferreira; Araújo, 2011).

Neste e em outros casos de musealização de restos humanos - seja em fotografias ou máscaras mortuárias - acredito ser necessário um profundo debate sobre as reverberações dessas imagens na economia de símbolos, nas ações relativas à "patrimonialização das diferenças" (Abreu, 2012) e, especialmente, nas discussões sobre o papel dos museus e os princípios éticos de seus profissionais. Questões aqui tangenciadas a partir das consequências da musealização dos restos mortais do cangaço que, até hoje, aguardam um desfecho e acionam memórias fortemente enraizadas em nosso imaginário.

\section{Referências}

ABREU, Regina. Emblemas da nacionalidade: o culto a Euclides da Cunha. Revista Brasileira de Ciências Sociais, São Paulo, n. 24, p. 66-85, 1994.

Patrimônio: ampliação do conceito e processos de patrimonialização. In: CURY, Marília Xavier; VANSCONCELLOS, Camilo de Mello; ORTIZ,Joana (Org.). Questões indígenas e museus: debates e possibilidades. São Paulo: MAE-USP; Secretaria de Estado da Cultura-SP, 2012.

ALBUQUERQUE JÚNIOR, Durval Muniz de. A invenção do Nordeste e outras artes. 5. ed. São Paulo: Cortez, 2011.

ARAÚJO, Antônio Amauru Correa de. Maria Bonita, a mulher de Lampião.

Salvador: Assembleia Legistativa da Bahia, 2009.

ARAÚJO, Antônio Amaury Correa de; BONFIM, Luiz Rubem. Lampião e as cabeças cortadas. Paulo Afonso, BA: GrafTech, 2008.

ARAÚJO, Germana Gonçalves de. Retratos e relatos sobre Maria na fotografia de Benjamim Abrahão. In: FERREIRA,Vera;ARAÚJO, Germana Gonçalves de (Org.). Bonita Maria do Capitão. Salvador: EDUNEB, 2011.

BRITTO, Clovis Carvalho. Gramática expositiva das coisas: a poética alquímica dos museus - casas de Cora Coralina e de Maria Bonita. 2016. 185 f. Dissertação (Mestrado em Museologia) - Faculdade de Filosofia e Ciências Humanas, Universidade Federal da Bahia, Salvador, 2016a.

Mulheres a ferro e fogo: reflexões sobre a musealização do cangaço. Estudos Históricos, Rio de Janeiro, v. 29 , n. 57, p. 49-66, 2006 b.

BOURDIEU, Pierre. A economia das trocas simbólicas. São Paulo: Perspectiva, 2007.

CASTRO, Celso; CUNHA, Olívia. Quando o campo é o arquivo. Estudos Históricos, Rio de Janeiro, n. 36, p. 3-5, 2005. 
CLEMENTE, Marcos Edilson de Araújo. Cangaço e cangaceiros: histórias e imagens fotográficas do tempo de Lampião. Fênix, v. 4, n. 4, p. 1-18, 2007.

CÓDIGO DE ÉTICA PROFISSIONAL. Conselho Internacional de Museus. ICOM: 15. Assembleia Geral do ICOM, Buenos Aires, 1986.

CÓdigo DEONTOLÓGICO PARA MUSEUS. Conselho Internacional de Museus. ICOM: 20. ${ }^{a}$ Assembleia Geral do ICOM, Barcelona, 2001.

CURY, Marília Xavier. Exposição: concepção, montagem e avaliação. São Paulo: Annablume, 2005.

DAS, Veena. Critical events: an anthropological perspective on contemporary India. Delhi: Oxford University Press, 1995.

FERNANDES, Cleudemar Alves. Discurso e produção de subjetividade em Michel Foucault. Laboratório de Estudos Discursivos Foucaultianos, Uberlândia-MG, Ano 2, p. 1-16, 2011.

FERREIRA,Vera; ARAÚJO, Germana (Org.). Bonita Maria do Capitão. Salvador: EDUNEB, 2011.

FOUCAULT, Michel. História da sexualidade: o cuidado de si. 10. ed. Rio de Janeiro: Edições Graal, 1988. O nascimento da clínica. Rio de Janeiro: Forense Universitária, 1987.

GRUNSPAN-JASMIN, Elise. Lampião senhor do sertão: vidas e mortes de um cangaceiro. São Paulo: EDUSP, 2001. HOLANDA, Aurélio Buarque de. Feira de cabeças. Diário Oficial do Estado de Pernambuco, Ano IX, jul. 1995.

KIM, Joon Ho. Exposição de corpos humanos: o uso de cadáveres como entretenimento e mercadoria. Mana, Rio de Janeiro, n. 18, v. 2, p. 309-348, 2012.

LATOUR, Bruno. Jamais fomos modernos: ensaio de antropologia simétrica. Rio de Janeiro: Editora 34, 1994.

LIMA, Estácio de. O mundo estranho dos cangaceiros. Salvador: Itapoã, 1965.

LIMA, João de Sousa. A trajetória guerreira de Maria Bonita: a rainha do cangaço. Paulo Afonso, BA: FonteViva, 2005.

MELLO, Frederico Pernambucano de. Estrelas de couro: a estética do cangaço. São Paulo: Escrituras, 2010.

Guerreiros do sol: violência e banditismo no Nordeste do Brasil. São Paulo: A Girafa Editora, 2004.

MEMMI, Dominique. Faire vivre et laisser mourir: le gouvernement contemporain de la naissance et de la mort. Paris: La découverte, 2003.

QUEIROZ, Marijara Souza. Museu, memória e a morte: um estudo a partir da coleção de quadros de cabelos da Fundação Instituto Feminino da Bahia. 2004. Dissertação (Mestrado em Artes Visuais), Universidade Federal da Bahia, 2004.

SANTELMO, Amador. Vida, aventuras e morte de Lampião e Maria Bonita. Rio de Janeiro: Livraria Antunes, 1954.

SANTOS, Simão Pedro dos. Dedos cravejados de brilhantes, chapéus de estrelas carregados: a épica dos cangaceiros na literatura de cordel. 2015. 209 f. Tese (Doutorado em Literatura Brasileira) - Departamento de Letras Vernáculas, Universidade Federal do Rio de Janeiro, Rio de Janeiro, 2015.

SELIGMANN-SILVA, Márcio. Narrar o trauma - a questão dos testemunhos de catástrofes históricas. Psicologia Clínica, Rio de Janeiro, v. 20, n. 1, p. 65-82, 2008.

SERRA, Ordep. Sobre psiquiatria, candomblé e museus. Caderno CRH, Salvador, v. 19, n. 47, p. 309-323, maio/ ago. 2006.

SILVA, David Roberto Bandeira da. Relíquias do cangaço: uma oferenda de apetrechos. Revista Leituras da História, n. 52 , ago. 2012 .

SILVA, Telma Camargo da. Musealização de eventos críticos: análise da tensão entre múltiplas narrativas da dor. XXXIV Encontro Anual da ANPOCS, Caxambu, 2010. 


\title{
Revisiting a "collection of heads": notes on the musealization of human remains of the cangaço
}

\begin{abstract}
The paper investigates the museumalization of mortal remains of the cangaço from the trajectory of the heads of Maria Bonita and Lampião. It analyzes the collection of heads from the point of view of the "consumption of the tragic", underlining how they contributed to the realization of an anti-museum and to the debates on ethical questions about necrophilia in museums. It shows how the musealization of the cangaceiros' heads contributes to the reconstruction of the interfaces between Anthropology, Museology and museums, evidencing the transformations in these artifacts: human remains as evidence of crime; trophies of war; scientific objects and museum collections. Analyzes highlight strategies of archiving, manufacturing and consecration of legacies in the plots of a symbol economy on the cangaço and the uses on the human spoils (considered like sensible objects) in the museums.
\end{abstract}

Keywords: Human remains, cangaço, musealization, sensitive objects, ethic.

\section{Revisando una "colección de cabezas": notas sobre la musealización de restos mortales del cangaço}

\section{Resumen}

El trabajo investiga la musealización de despojos mortales del bandolerismo a partir de la trayectoria de las cabezas de María Bonita y Lampião. Analiza la colección de cabezas bajo el punto de vista del "consumo de lo trágico", subrayando cómo contribuyeron para la efectivización de un antimuseo y para los debates sobre cuestiones éticas en torno a la necrofilia en los museos. Muestra cómo la musealización de las cabezas de los bandoleros contribuye para la reconstrucción de las interfaces entre Antropología, Museología y museos, evidenciando las transformaciones en estos artefactos: los restos humanos como evidencia del crimen; trofeos de guerra; objetos científicos y colecciones de museos. Los análisis destacan las estrategias de archivo, fabricación y consagración de legados en las tramas de una economía de símbolos en el bandolerismo y los usos del botín humano (considerados como objetos sensibles) en los museos.

Palabras clave: Restos mortales, bandolerismo, musealización, objetos sensibles, ética. 